\title{
Synthetic and non-synthetic anthropogenic fibers in a river under the impact of Paris Megacity:
} Sampling methodological aspects and flux estimations

\author{
Rachid Dris ${ }^{\mathrm{a},}$, Johnny Gasperi ${ }^{\text {a, }}$ Vincent Rocher ${ }^{\mathrm{b}}$, Bruno Tassin ${ }^{\mathrm{a}}$ \\ a Université Paris-Est, Laboratoire Eau, Environnement, Systèmes Urbains (LEESU), UMR MA \\ 102 AgroParisTech, 61 Avenue du Général de Gaulle, Créteil Cedex, France
}

b Syndicat Interdépartemental Pour l'Assainissement de l'Agglomération Parisienne,
Direction du Développement et de la Prospective, 82 Avenue Kléber, Colombes, France

\section{Introduction}

Fibers world production reached 100 million metric tons in 2016 (International Cotton Advisory Committee, 2017) including natural fibers (like cotton) and manmade fibers either artificial (like rayon/viscose) or synthetic (polypropylene, polyamide, etc.). The manmade fraction represents 65 million metric tons for the synthetic fibers which consist of petrochemical polymers, in addition to 6.5 million metric tons of artificial fibers which are regenerated cellulose. Either natural or manmade, processed fibers are present in our daily life and serve for many domestic uses, namely clothes, bed linens, curtains and carpets, chair coverings and upholstery. They are also used in agriculture and fisheries, civil engineering (geotextiles) and more generally in the industry (car, planes, ...). As a consequence, to the widespread use of products composed of fibers and their more or less easy abrasion, fibers are now found everywhere in our surrounding environment.

As the production of fibers increases of about $2 \%$ per year, fibers are more and more present in the environment. The development of research on microplastics has made it possible to draw attention to the presence of fibers in the environment including marine (Lusher et al., 2015) or continental waters (Mani et al., 2015). It also helped reveal the high amount of fibers that are daily introduced to the environment through wastewater treatment plant effluents (Murphy et al., 2016; Talvitie et al., 2015; Browne et al., 2011). Moreover, they have been detected in indoor air in apartments and offices, as well as in outdoor air (Dris et al., 2017).

Because of their small size the aesthetic nuisance of these fibers is almost inexistent. However, because of their L/D ratio they are easily ingested by organisms (Remy et al., 2015; Lusher et al., 2013; Sanchez et al., 2014). This could cause physical harm most likely related to a disruption of the digestive system (blocking of intestinal tract, false sensation of satiation, etc.) as it was shown for microplastic particles (Farrell and Nelson, 2013; Tourinho et al., 2010; Derraik, 2002; Carr et al., 2012; Cole et al., 2013). It was also shown that the biota ingests various fibers, including both synthetic and non-synthetic ones. The presence of rayon was shown in the organism of fish in the English Channel (Lusher et al., 2013; Lusher et al., 2014). A study also showed the presence of cotton textile fibers in fish from various European seas (Collard et al., 2015). The second category of risks pertains to the fact that these fibers carry a "cocktail of chemicals" they either transport over long distances or release inside an organism after being ingested. Such chemicals are introduced into the plastic polymers during production or may adsorb to them once in the environment (Rochman and Browne, 2013). Fibers made of natural polymers should also be a concern as they are died with carcinogenic substances like the dyes direct red 28 and direct blue 22 (Remy et al., 2015) and contain known harmful additives as flame retardants.

In contrast to the ubiquity of fibers in the environments and to the fact that they get ingested and are potentially harmful, studies focusing on this contamination are very rare. The body of scientific work related 
to the analyze of anthropogenic particles in environmental waters is mainly oriented towards microplastic particles shaped as fragments, pelleted or spheres. Moreover, while synthetic fibers are often included as a minor sub-category of microplastics, the natural and artificial fibers are (with very few exceptions (Lusher et al., 2013)) automatically dismissed.

Due to these observations, and in relation to the fact that no study focused solely on fibers, it appears necessary to acquire more data in relation to their occurrence in the environment. In contrast with previous studies dealing with microplastics in freshwater, this study focused exclusively in fibers (regardless of the material compositing them) and other shapes of microplastics were not considered. The reasoning behind this decision is twofold: i) fibers are difficult to quantify and require specific methods for sampling and analyzing and ii) the ubiquity of fibers was shown in various studies making it of utmost importance to document this specific contamination. Mineral fibers were excluded.

It aimed at i) deriving insights about methodologies for river water sampling regarding fiber quantification and ii) providing sufficient knowledge on fiber levels of contaminations leading to annual fluxes estimations.

The first aim was considered in order to address the representativeness of sampling microplastics in a river, which is an environment with a highly turbulent flow. The short-term temporal variability and the distribution of the fibers through the water section were therefore investigated. For the second aim the variations of the fibers over a period of 19 months in five different sites, both upstream and downstream and urban environment were determined. With this new insight, first attempts to flux estimations of fibers in a river impacted by a megacity were carried out.

\section{Material and Methods}

The Paris Megacity was considered. This megacity is one the world's 40 largest with a population of over 10 million (INSEE, 2013). The Paris agglomeration is crossed by the Seine River; whose catchment drains an area of approximately $32,000 \mathrm{~km}^{2}$ from the river's headwaters to Paris. This catchment combines intense anthropogenic pressures with a very limited dilution factor due to the low average flow $\left(350 \mathrm{~m}^{3} \cdot \mathrm{s}^{-1}\right.$ in Paris). The transect considered of the Seine River receives two incoming tributaries (Marne and Oise Rivers), the effluents from several wastewater treatment plants (WWTPs) $\left(20-22 \mathrm{~m}^{3} \cdot \mathrm{s}^{-1}\right.$ ) as well as discharges during wet weather periods (runoff, combined sewer overflows (CSOs), etc.).

\subsection{Sampling device}

Sampling was performed with a homemade device coupling a plankton net (mesh size: $80 \mu \mathrm{m}-725-\mathrm{cm}^{2}$ sampling surface area) with a propeller-type current meter (OTT C2'10.150' — enabling measurement of water velocity in the range of 0.025 to $5 \mathrm{~m} \cdot \mathrm{s}^{-1}$ ). Although plankton nets are typically deployed vertically in freshwater to sample phytoplankton biomasses over a given depth, this net was modified to allow horizontally-flowing water through it. The net was deployed from bridges in order to sample at the middle of the section (points P1 to P5, Fig. 1). The local horizontal flow velocity was measured simultaneously in order to evaluate the sampled volume. A triplicate for velocity measurements was carried out. Clogging during sampling may occur due to suspended matter in the Seine River. Preliminary tests to prevent net clogging were performed. It was shown that the net stopped from sampling when the volume surpassed $8 \mathrm{~m}^{3}$, in conditions of total suspend solid levels over 10 $\mathrm{mg} \cdot \mathrm{L}^{-1}$. Quicker clogging is expected with higher suspended solid levels. To ensure the absence of clogging, the sampled volume was always kept largely below the $8 \mathrm{~m}^{3}$ threshold.

The net was exposed for $1 \mathrm{~min}$ as a compromise between increased representativeness, avoidance of 
clogging and the possibility of sampling between the relatively frequent barge traffic. However, during low flow conditions longer exposure durations have been implemented. The surface layer of the water column was taken into consideration (i.e. a $0.05-0.35$ m layer).

Following collection, the net was thoroughly rinsed three times from the outside using river water. Before monitoring, during one sampling, rinsing efficiency was tested. The first three rinses revealed a cumulative number of 61 fibers, while just 2 fibers were found in the fourth rinse.

\subsection{Sampling approach}

\subsubsection{Short scale temporal variability}

Two separate campaigns were carried out in order to assess the short scale temporal variability of microplastic concentrations. During the first campaign held on 12th March 2015 at the P1 site (Fig. 1-Marne River) 6 samples were collected over a 2-h period (10:52 am to 00:48 pm). For the 1-minute exposure, the average volume sampled equaled $2.21 \mathrm{~m}^{3}$ and a river flow of $144 \mathrm{~m}^{3} \cdot \mathrm{s}^{-1}$ was recorded. The second campaign was held on 6th July 2015 at the same site. As a consequence of the lower river flow in summer $\left(24 \mathrm{~m}^{-3} \cdot \mathrm{s}^{-1}\right)$, a 3-minute exposure was chosen for the 6 samplings. An average volume of $2.72 \mathrm{~m}^{3}$ was sampled. The first sampling occurred at 00:03 pm, and the last one at 03:00 pm.
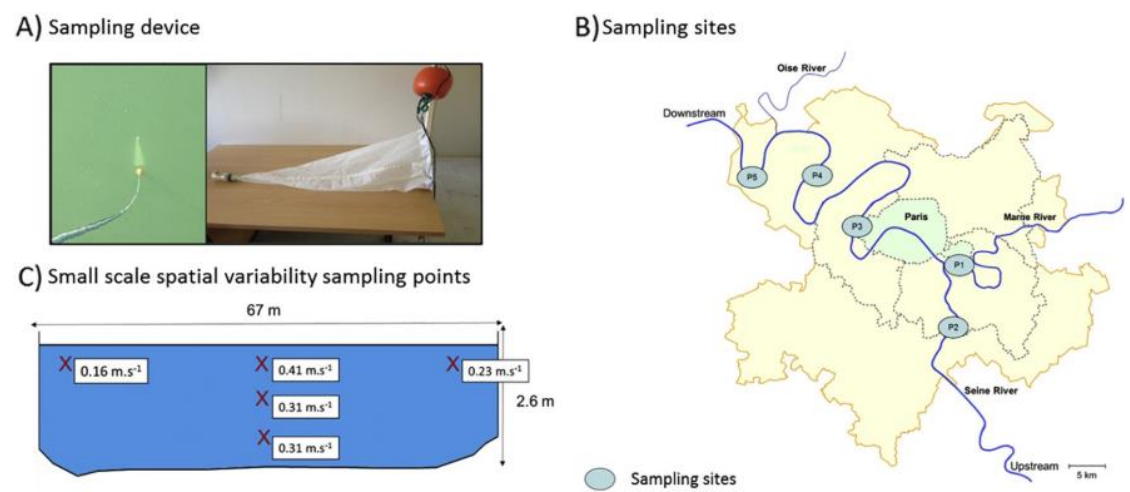

Fig. 1. A presentation of the sampling device, the sampling sites and the different sampling points during the small scale spatial variability and their respective velocities.

\subsubsection{Distribution through the water section}

At the P1 station, triplicates at five different points in the river section were sampled on 23rd April 2015 (flow: $69 \mathrm{~m}^{3} \cdot \mathrm{s}^{-1}$, sampling duration: $3 \mathrm{~min}$ ). The river in this site has steep artificial riverbanks, its width is of $67 \mathrm{~m}$ while its depth during sampling was of $2.6 \mathrm{~m}$ (determined using an echo sounder). The sampling took place just below the surface (right bank, middle, left bank) and at different depths (1 $\mathrm{m}$ and $2 \mathrm{~m})$ in the middle of the river. The right and left bank sampling points were carried out at a distance of $5 \mathrm{~m}$ from the banks. All sampling was performed within $3 \mathrm{~h}$. 
A 19-month monitoring (from April 2014 to December 2015, except for January and August 2015) was conducted in order to provide an idea for the large scale spatial-temporal variability. Once a month, five samples were extracted at four stations (P2-P5) on the Seine River from upstream of Paris to downstream. P2 represents an upstream point before any input of the Parisian WWTPs while P3 to P5 are located respectively: directly downstream the city of Paris, downstream the WWTP of Seine Centre, and downstream the largest WWTP of France, Seine Aval. One station on the Marne River (P1) was also considered (Fig. 1) as it is the main tributary of the Seine River.

This set-up led to 19 sampling campaigns. Sampling at the five stations was always performed on the same day. The sampling duration was set at $1 \mathrm{~min}$, which ensured that the net would not clog regardless of the river flow and suspended matter concentration, in all sites and even during high flow events. The collected volumes ranged between

0.2 and $4.0 \mathrm{~m}^{3}$ over the monitoring period. This monitoring would also yield an overview of concentrations under various water flow conditions varying from 21 to $856 \mathrm{~m}^{3} \cdot \mathrm{s}^{-1}$.

\subsection{Sample purification}

Samples are quite often biota-rich or highly concentrated in natural organic debris as well as mineral debris. These two fractions, given that they would hinder the following steps (filtration, observation and characterization), need to be removed. The protocol was adapted from a method previously developed by a German team (Mintenig et al., 2014). Briefly, the first step calls for placing $1 \mathrm{~g}$ of SDS (Sodium dodecyl sulfate), which is an anionic surfactant, in contact with the samples. After $24 \mathrm{~h}$ in $70{ }^{\circ} \mathrm{C}, 1 \mathrm{ml}$ of biozyme $\mathrm{F}$ (containing lipase) and biozyme SE (containing protease and amylase) were added to the samples, which were subsequently incubated at $40{ }^{\circ} \mathrm{C}$ for over $48 \mathrm{~h}$. Any material of a biological origin was then further reduced with $15 \mathrm{ml}$ of hydrogen peroxide $\left(30 \% \mathrm{H}_{2} \mathrm{O}_{2}\right)$ at $40{ }^{\circ} \mathrm{C}$ for $48 \mathrm{~h}$. The samples were homogenized from one step to the next.

Reducing the organic fraction on its own is insufficient to enable an easy microplastic observation and analysis. The mineral fraction must also be efficiently removed. In this work, zinc chloride $\left(\mathrm{ZnCl}_{2}\right.$, made available by Carlroth), which can attain a density above $1.6 \mathrm{~g} \cdot \mathrm{cm}^{-3}$, was chosen. The solution was prepared by placing $700 \mathrm{~g}$ of $\mathrm{ZnCl}_{2}$ crystals into $500 \mathrm{ml}$ of water run through osmosis and filtration. For each prepared solution, the final density was verified by weighing. Regular weighing has revealed a density of $1.660 \mathrm{~g} \cdot \mathrm{cm}^{-3}\left( \pm 0.060 \mathrm{~g} \cdot \mathrm{cm}^{-3}\right)$. Following natural organic matter removal, the samples were placed in an oven to reduce their volume, before being transferred into a separation funnel and adding $\mathrm{ZnCl}_{2}$. The solution was then stirred for $3 \mathrm{~min}$. After a few hours (from $2 \mathrm{~h}$ to $24 \mathrm{~h}$ depending on sample type), the mineral particles sank and were eliminated. The supernatant was kept and vacuum filtered on glass fiber filters (GF/A Whatman filters, $1.6 \mu \mathrm{m}$ mesh size).

\subsection{Contamination mitigation and assessment}

Many studies have reported that samples are often contaminated with fibrous microplastics, apparently stemming from textiles. In a study focused on textile fibers taking precautions to limit and assess contamination is very important. The samples were permanently covered with an aluminum foil in order to prevent airborne contamination. Only clean glass vessels were used, yet fibers and microplastics can very easily adhere to such vessels. All vessels were therefore heated to $500{ }^{\circ} \mathrm{C}$ for $4 \mathrm{~h}$ prior to use so as to eliminate any microplastic polymers still adhering to them. Moreover, the vessels were covered with aluminum foil immediately after retrieval from the oven. The glass fiber filters might have been contaminated even before 
their first use. In fact, a direct observation of filters from their box sometimes indicated fibers on them. Consequently, the filters were also heated to $500{ }^{\circ} \mathrm{C}$ for $4 \mathrm{~h}$ before filtration. An inspection of select filters after heating did not reveal any fibers or particles attesting to the efficiency of the method. Except for the nylon nets introduced, all use of plastic items was avoided. Cotton lab coats were worn during all laboratory procedures.

While contamination can be easily avoided during many steps, filtration is a more delicate process since the samples cannot be covered.

Blanks were performed and subjected to the same treatments as the samples. Between 0 and 3 fibers per blank filter were observed, which is negligible as the number of fibers in the samples is much greater than the potential contamination.

\subsection{Quantification and characterization}

The filters were observed with a stereomicroscope (Leica MZ12) coupled to an image analysis software (HISTOLAB $囚)$ at a magnification of " $\times 16$ ". Higher magnification was needed for some fibers that could barely be identified (too small, transparent, etc.). The length of all fibers was measured. It was decided herein to assess anthropogenic fibers including natural, artificial as well as the synthetic fibers. In order to provide nonetheless an idea of the nature of the fibers, characterization was used for a small proportion of the fibers. It served also to verify if the considered fibers with the visual methods correspond in fact to organic anthropogenic fibers. The low amount of the fibers characterized do not allow a strong extrapolation of the estimated proportions to all the fibers.

In fact, 25 fibers were selected randomly and their nature was identified. A Thermo Scientific corporation (i.e. the Nicolet Continuum model) Fourier Transform InfraRed (FTIR) microspectroscope was employed with the reflection mode. An objective of $(\times 10)$ was used to detect the targeted fibers, and the analysis was carried out with the $(\times 32)$ lens. A signal blank was measured every $100 \mathrm{~min}$.

\section{Results and discussion \\ 3.1. Fiber morphology and nature}

Fibers of various colors were observed, with a predominance of blue fibers. The fact that they have none natural colors indicates that the encountered fibers are industrially processed. The diameter of these fibers vary between 5 and $100 \mu \mathrm{m},(25 \mu \mathrm{m}$ mean). Based on our sampling and observation methodology, the length dimension distribution shows that the [250-450 $\mu \mathrm{m}$ ] fraction is the most abundant (Fig. 2). This proportion decreases towards the larger size ranges. The smallest size range of [50-250 $\mu \mathrm{m}]$ contains fewer fibers, a finding that may be correlated with the fact that the shorter the fibers are, the easiest they may pass through the $80-\mu \mathrm{m}$ net.

Automatic comparison using the analyzing software of the obtained spectra with the database showed a correspondence for 15 of the analyzed fibers with rayon and for 1 with cotton. However, knowing that differences between rayon and cotton spectra are very minim and due to the complexity of the spectra of environmental particles, it is hard to assure of the accuracy of this distinction. Nonetheless, this result indicates that 16 fibers correspond to cellulosic fibers. The remaining fibers (9 fibers) are all synthetic. Five of these fibers correspond to PET, while two correspond to PP and one to PA. The last fiber is a PET-PUR blend. Based on their nature, all characterized fibers are likely textile fibers. These results cannot be used as a representative estimation of the proportion of the microplastics among the fibers in the Seine River but illustrate that the Seine 
River is contaminated with a mixture of fibers to which the biota will be exposed. This reinforces our opinion that all fibers including natural fibers, artificial fibers and synthetic fibers need to be assessed and studied.

\subsection{Short scale temporal variability}

During the first sampling campaign, concentrations varied between 38.2 and 101.6 fibers $\cdot \mathrm{m}^{-3}$ with a mean concentration of 66.2 fibers $\cdot \mathrm{m}^{-3}$ (Fig. 3). The coefficient of variation equals approx. $45 \%($ with $n=6)$. This variability includes the short term environmental variability and all the uncertainties that could be induced by the used methodologies from sampling to identifying the fibers. Unpublished preliminary tests showed that in our case, the laboratory processing steps along with the identification lead to a maximum variability of $5 \%$ (based on three different users). As a consequence, environmental variations and sampling uncertainties lead to the major part of this global variation.

If the sampling method is considered to not inherently affect the variability; the variation of concentrations might be due to turbulent water or variations on microplastic inputs. Sporadic inputs from runoff could for instance be expected during this high water flow event. This pattern could also be due to the short sampling duration. Accordingly, the net was deployed three times longer during the second campaign ( 3 min vs. 1 min), leading to concentrations ranging between 18.7 and 38.6 fibers $\cdot \mathrm{m}^{-3}$, witha mean of 30.4 fibers $\cdot \mathrm{m}^{-3}$. The coefficient of variation dropped to $26 \%(n=6)$. This would be consistent with the fact that longer samplings reduce the proportional impact of sporadic inputs.

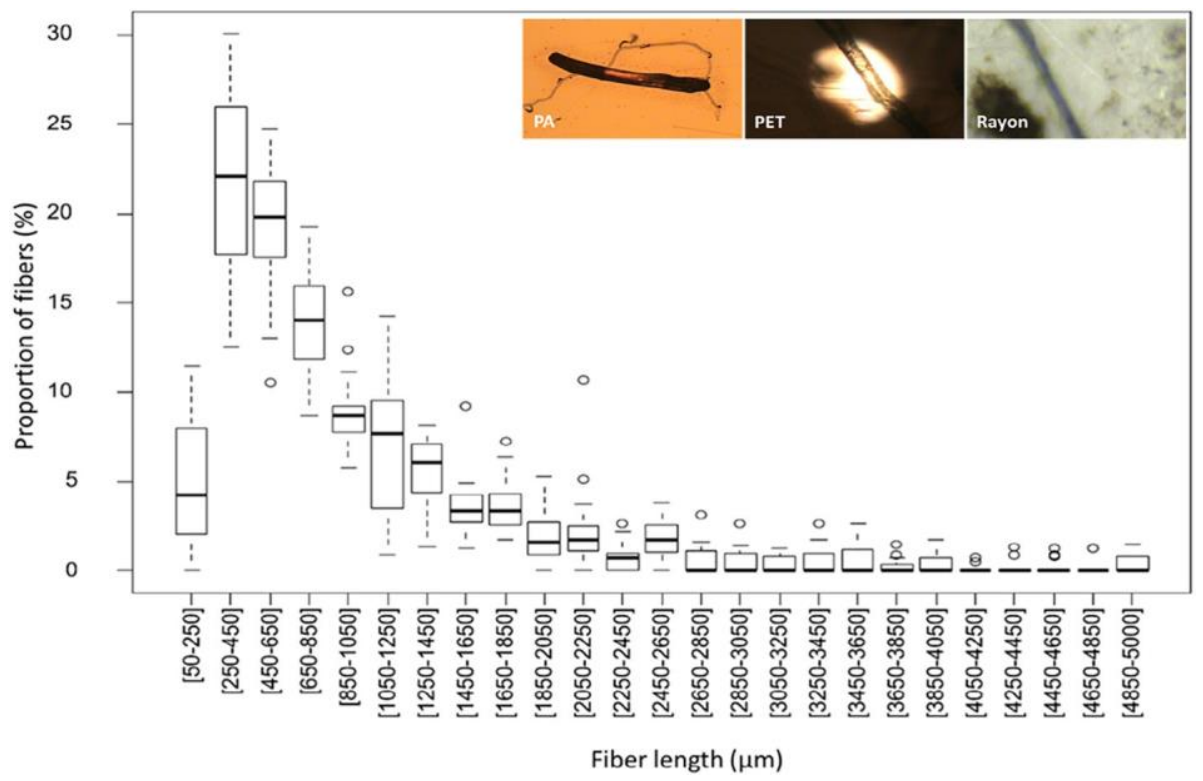

Fig. 2. Fiber size distribution in river samples (based on $n=15$ samples and 1664 measured fibers). Boxplots are shown from bottom to top with: [Lower quartile $-1.5 *$ Interquartile range], [Lower quartile], [Median], [Upper quartile], [Upper quartile $+1.5 *$ Interquartile range]. Outliers are displayed as isolated points. 


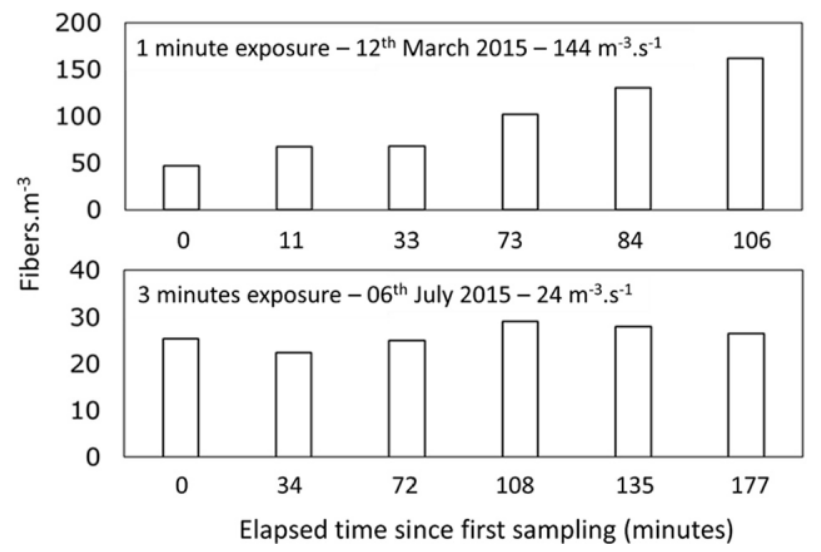

Fig. 3. Small scale temporal variability of fiber concentrations.

Triplicates of samples in the sub-surface displayed concentrations of 16.8-21.3-24.7 fibers $\mathrm{m}^{-3}$ at the middle and higher concentrations were observed on the left bank (52.461.0-87.7 fibers $\left.\cdot \mathrm{m}^{-3}\right)$ and on the right bank $\left(32.1-34.8-46.4\right.$ fibers $\left.\cdot \mathrm{m}^{-3}\right)$. The coefficient of variation among the nine 3 -minute sub-surface samplings equals approx. $53 \%$, which is twice the coefficient of variation derived from the second campaign of short-term temporal variability. In knowing that this campaign was conducted under the same conditions (3-minute samplings within $3 \mathrm{~h}$ ), the level of sampling precision and short-term temporal variability do not, on their own, explain the observed fluctuations. This finding indicates a potential difference in concentration between the middle of the watercourse and its banks. The higher concentrations observed near the banks might be related to the effect of intense river traffic within the Paris Megacity. It can in fact be visually observed that a boat passing generates waves that drive floating debris, including macroplastics, towards the banks. Similar behavior could be expected for microplastics. Concentrations of 19.0-20.2-28.2 fibers $\cdot \mathrm{m}^{-3}$ were found at a $1-\mathrm{m}$ depth and 13.7-16.9-19.1 fibers $\cdot \mathrm{m}^{-3}$ at a depth of $2 \mathrm{~m}$. In considering the nine samples collected on the vertical in the middle of the section at

all three depths, a coefficient of variation of $21 \%$ was found, thus indicating that vertical variability is two times smaller than the lateral variability. Floating nets are widely used, like in marine environments. While it is usually accepted, although questionable, in marine water that fibers and microplastics float near the surface, turbulence and current conditions homogenize their distribution throughout the water section in rivers, especially since freshwater density is lower than marine water one. Boat traffic also contributes, to some 
extent, to the resuspension of settling particles (Vilmin et al., 2015).

\section{4. $\quad$ Monthly monitoring}

Concentrations during the year in the Marne River (P1) lie between 5.7 and 398.0 fibers $\cdot \mathrm{m}^{-3}$, corresponding to a mean concentration of $100.6 \pm 99.9$ fibers $\cdot \mathrm{m}^{-3}$ (mean \pm standard deviation, $\mathrm{n}=19)$. From the upstream to downstream points, the recorded concentrations are respectively: $48.5 \pm 98.5$ fibers $\cdot \mathrm{m}^{-3}(\mathrm{P} 2), 27.9 \pm 26.3$ fibers $\cdot \mathrm{m}^{-3}(\mathrm{P} 3), 27.9 \pm$ 40.3 fibers $\cdot \mathrm{m}^{-3}(\mathrm{P} 4)$, and $22.1 \pm 25.3 \mathrm{fibers} \cdot \mathrm{m}^{-3}(\mathrm{P} 5)$. Detailed results are displayed below (Fig. 4).

The coefficient of variation on each station lies between $94 \%$ and $203 \%$, which is greater than the short-term temporal variability, which could suggest that even if minimal, variations occur throughout the year. Interestingly, variations seem to occur in a similar manner across the various sites. When verifying the pairwise correlation between sites, the Spearman's rank correlation coefficients confirm that the various sites present correlated concentration levels (except between P1 and P3), which could indicate that global factors varying equally for all sites are more likely to affect concentrations than local or one-time factors. The variations in diffuse inputs or seasonal changes might be the cause.

A correlation with river flow variations was suspected. However, no clear correlation between water flows and concentrations was highlighted $\left(0.09 \mathrm{~b} \mathrm{R}^{2} \mathrm{~b} 0.24\right)$. A tendency for fiber levels to always remain low during high water flow periods can nonetheless be observed here. During low water flow periods, the levels vary to a much greater extent and could be influenced by different parameters, such as fiber input, either from singular sources (either continuous like WWTPs or discontinuous like CSOs), diffusive sources (atmospheric fallout) (Dris et al., 2016) or a possible re-suspension of fibers from the sediments.

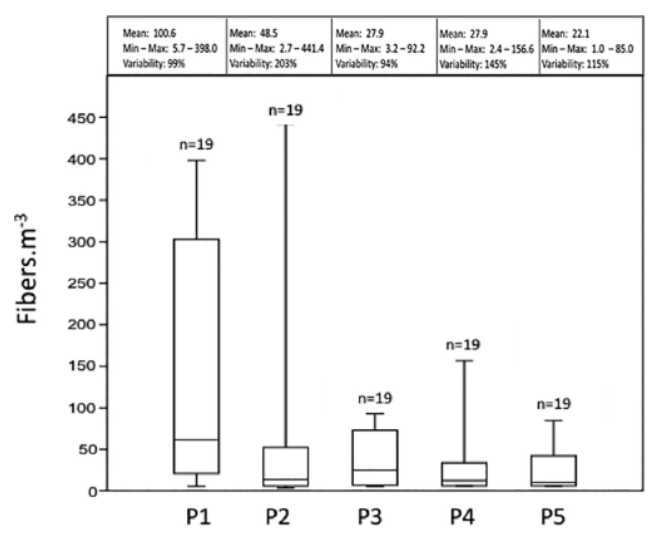

Fig. 4. Concentrations of fibers on each of the five sites for 19 monthly samplings. 


\subsection{Annual fluxes}

The annual fiber fluxes in the Seine River using the 19 individual fluxes were calculated at each site. The averages are respectively from P1 to P5 of $1.4 \times 10^{11}, 1.7 \times 10^{11}, 1.6 \times 10^{11}$, $1.3 \times 10^{11}$ and $1.8 \times 10^{11}$

fibers per year. Both the upstream point (P2) and downstream point (P5) display nearly similar fluxes. The increase between these two stations is only $6 \%$, i.e. much smaller than the uncertainty induced by the short scale variabilities discussed above. Consequently, as regards the fibers, it seems that the impact generated by the Paris Megacity cannot be distinguished. The minimum and maximum estimated fluxes for the most downstream site P5 are respectively 2.8 $\times 10^{10}$ and $6.1 \times 10^{11}$ fibers per year, with a mean value of $1.8 \times 10^{11}$.

The current state of knowledge does not provide an understanding or explanation of the nonincreasing pattern from upstream to downstream. Given the various potential fiber inputs located between the sites, the fact that fiber fluxes are not significantly differ ent from upstream to downstream does not seem intuitive. Between P2 and P5, two confluents of the Seine (Marne and Oise Rivers) are encountered, along with three wastewater treatment plant outlets (Seine Amont, Seine Centre and Seine Aval), including the largest one in Europe, various CSOs and the densely-populated city of Paris. Sinks to counterbalance these inputs could explain the fact that similar fluxes are found upstream and downstream of Paris. A major role related to fiber sedimentation and deposition on the banks is expected. In recognizing the short time frame required to transport particles from the upstream point downstream (an estimated $72 \mathrm{~h}$ between P2 and P5, based on average water velocities), degradation was not considered to be a plausible explanation but further knowledge on fiber dynamics are required.

\section{Importance of used size mesh}

Microplastics are unique contaminants characterized by a continuum of sizes from $1 \mu \mathrm{m}$ to $5 \mathrm{~mm}$ and often sampled by nets (Eriksen et al., 2013; Hidalgo-Ruz et al., 2012; Imhof et al., 2012; Moore et al., 2011) or sieves (Murphy et al., 2016; Carr et al., 2016), through which the microplastics, particularly the thin fibers, can pass. As presented in the introduction of this paper, various mesh sizes have been used in river water studies including $800 \mu \mathrm{m}$ (Moore et al., 2011), $500 \mu \mathrm{m}$ (Moore et al., 2011; Lechner et al., 2014), $330 \mu \mathrm{m}$ (Mani et al., 2015; Moore et al., 2011; McCormick et al., 2014; Yonkos et al., 2014) and $112 \mu \mathrm{m}$ (Zhang et al., 2015). As a consequence, results are not easy to compare. It can be easily assumed that a bias is introduced due to the chosen cutoff. Moreover, the real sampling cutoff, even if correlated with mesh size, differs to some extent. While it is impossible to directly estimate the probability of particles passing through a predetermined mesh size, comparisons among mesh sizes and an observation of the particle size distribution can assist future works in selecting the right mesh size. The average concentration of fibers collected with the $80 \mu \mathrm{m}$ mesh net equals 44 fibers $\cdot \mathrm{m}^{-3}(\mathrm{n}=95)$. For five samples not included in this article, sampling with a $330 \mu \mathrm{m}$ 
sized net yields an average concentration of 0.18 fibers $\cdot \mathrm{m}^{-3}$. This difference indicates that using the $80 \mu \mathrm{m}$ mesh size rather than the $330 \mu \mathrm{m}$ increases the probability of sampling fibers by 250 times. This result is to some extent lower than what was estimated in a study that found three orders of magnitude more microplastics in the $80 \mu \mathrm{m}$ net (Norén, 2007). For the fibers sampled in this work, none with a length shorter than the mesh size were observed. The smallest fiber observed with the $80 \mu \mathrm{m}$ net was $90 \mu \mathrm{m}$, with between $4 \%$ and $25 \%$ of the fibers being $330 \mu \mathrm{m}$ or smaller. On the other hand, fibers display an average diameter of $25 \mu \mathrm{m}$, i.e. less than the $80 \mu \mathrm{m}$ mesh size. It is difficult to determine whether a fiber would pass through a certain sized mesh. Such a determination would depend not only on its size but also on its 3D positioning since passing would be facilitated completely parallel to the meshes and hindered perpendicular to the meshes.

On the other hand, even though the collected fraction is now accessible, still no idea of the fraction passing through the nets can be obtained. While some small fibers were sampled, we ignore the amount that went uncollected. Consequently, typical results regarding microplastic pollution should always be treated with caution. Representativeness depends on the cutoff as well as debris presence inside the net and has yet to be determined. Further tests could be conducted in order to derive a more precise idea of what is passing through the nets. Sampling with a device that couples various mesh sizes, one directly behind the other, could help address this query. A laboratory test could also be performed with labmade fibers (Cole, 2016).

\subsection{Relevance of an approach considering all fibers}

While the microplastic definition based on particle size and shape characteristics is often discussed, no attention however gets paid to the nature and chemical definition that should be ascribed to a microplastic. The definition of plastic is not inherently simple, a feature that affects the microplastic definition. Given that the microplastic topic is mainly environmental, the definition of a microplastic should be based to a great extent on its potential impact.

Both natural and artificial fibers (principally rayon) have been neglected due to the commonly held perception that their rapid degradation does not cause any environmental damage. In our work however, these fibers were found in freshwater. Rayon had also already been found in previous works in marine environments and even in the gastrointestinal tract of fish in the English Channel (Lusher et al., 2013; Lusher et al., 2014). The presence of rayon in these fish indicates that, even though rayon is more readily degradable than synthetic fibers, it can still bypass wastewater treatment, be transported into the environment (by air, given that rayon was observed in atmospheric fallout, or by water), and stay long enough until being ingested. One type of rayon, viscose, was also found in the gut of various macrofauna species living in the Mediterranean. These species were of various trophic levels. The same study identified 225 two dyes on the rayon fibers, i.e.: direct red 28, and direct blue 22 (Remy et al., 2015). The authors also pointed out that these dyes are known to be carcinogenic for vertebrates. Other authors have indicated that cotton-based fibers can not only adsorb pollutants and contain many additives, but they 
can also facilitate pollutant and fiber availability to organisms through being degraded; on the other hand, synthetic fibers would deny the pollutants availability to the surrounding environment (Ladewig et al., 2015). As research has become focused on synthetic fibers, greater efforts are now needed to compare the natural and artificial categories. Degradation rates, as well as capacities to interact with both the pollutants and the biota, must be determined in order to better estimate the potential impact of these fibers.

This study shows that both synthetic and none synthetic fibers present high occurrences in freshwater. In general, studies deal exclusively with synthetic fibers and ignore the presence of other anthropogenic fibers. This is mainly due to the environmental persistence of the synthetic polymers and to the fact that previous ecotoxicological studies only tested the effect of synthetic particles on organisms.

\section{Conclusions and perspectives}

This article provides some new insight to the uncertainties that sampling methods could induce as well as data on fiber contaminations and fluxes in Paris freshwater. In this purpose, we advise the use of an $80 \mu \mathrm{m}$ mesh size net to limit fiber loss. However, with the clogging problem, small volumes (in comparison to the widely used $330 \mu \mathrm{m}$ mesh size net) would be necessary inducing less representativeness. The temporal variation campaigns proved that deploying the net for a longer time period ( $3 \mathrm{~min}$ vs. $1 \mathrm{~min}$ ) reduces variability between consecutive samples. As increasing sampling time is often complicated due to clogging problems in river, the only solution that can be immediately proposed for future work is multiplying the number of samples in opposition to increasing the volume. But further knowledge and efforts are required, as analyzing microplastics is time consuming. The best balance between repetitiveness and sampling time is yet to be determined.

Fiber variability throughout the water section was also assessed, revealing that concentrations are similar over the entire river depth while concentrations tend to rise near the banks. This pattern will somehow affect the flux estimations provided. However, in this work it was not taken into account. In fact, this campaign is a preliminary investigation and further work is needed. Mainly, other sites have to be considered, especially sites with a higher width (67 $\mathrm{m}$ in this study). If no pattern can be concluded, studies might have to always sample the middle point and both banks.

During the monthly monitoring campaigns at 5 different sites, concentrations varied similarly across the various sites. No direct correlation was highlighted between concentration levels and water flows. However, while concentration levels are variable during low water flows, they remain low as water flow increases. The concentration variability is therefore due in part to water flow, but also to other undetermined factors, likely related to the inputs. The estimated fluxes were similar upstream and downstream of the Paris Megacity. The impact of Paris therefore was not visible, and fibers did not appear to accumulate in the downstream direction. Further work is still needed to understand the various potential mechanisms and dynamics responsible for this pattern. Analyzing sediments is required in order to verify if 
sedimentation acts as a sink and causes fibers to not accumulate. Investigating the benthic boundary layer is also important as it could serve as the main transport route for the fibers in the Seine River.

The present study has helped fill some major knowledge gaps regarding the fibers in rivers, their occurrence, spatial-temporal distribution and fluxes. It also provided new insight for future studies regarding sampling methodologies. Yet on the other hand, a lack of knowledge on the literature about the fiber dynamics limits the interpretation possibilities for the observed patterns. It is of utmost urgency to identify the role of some mechanisms as sedimentation, re-suspension, fragmentation and riverbank deposition. Moreover, these mechanisms are expecting to affect differently the particles depending on their size, shape (fibers vs. fragments), polymer and density, which additives are present etc. making the understanding harder. A modeling approach as proposed recently in a study might help overcome these challenges (Besseling et al., 2017).

While this work opened up to a lot of questions that need further investigations, it provided also some certainties, at least for the Parisian freshwater. In fact, it was proved that fibers are highly present and that they can have different natures, either natural (cotton, wool...), artificial (rayon mainly) or synthetic (petrochemicals). It is important to recall that one of the purposes of determining microplastic concentrations in freshwater is to help subsequent works investigate the potential ecotoxicological impact of this contamination. It is encouraged that future studies on the impact of fibers include also non synthetic ones. Their potential impact is completely unknown and the effect of their association with chemicals and additives is yet to be determined.

\section{Acknowledgments}

The authors thank the technical team of the SIAAP and especially Erwan Garcia Gonzalez and Julien Pouillaude. The authors address sincere thanks to Anne Chabas from the LISA (Laboratoire Interuniversitaire des Systemes Atmospheriques). This work was funded by the region IledeFrance Research Network on Sustainable Development (R2DS Ile-deFrance) (Grant Number: 2013-02) and the PIREN-Seine.

\section{References}

Besseling, E., Quik, J.T.K., Sun, M., Koelmans, A.A., 2017. Fate of nanoand microplastic in freshwater systems: a modeling study. Environ. Pollut. 220 (Part A), $540-548$.

Browne, M.A., et al., 2011. Accumulation of microplastic on shorelines woldwide: sources and sinks. Environ. Sci. Technol. 45, 9175-9179.

Carr, K.E., Smyth, S.H., McCullough, M.T., Morris, J.F., Moyes, S.M., 2012. 
Morphological as- pects of interactions between microparticles and mammalian cells: intestinal uptake and onward movement. Prog. Histochem. Cytochem. 46, 185-252.

Carr, S.A., Liu, J., Tesoro, A.G., 2016. Transport and fate of microplastic particles in waste- water treatment plants. Water Res. 91, 174-182.

Cole, M., 2016. A novel method for preparing microplastic fibers. Sci. Rep. 6, 34519. Cole, M., et al., 2013. Microplastic ingestion by Zooplankton. Environ. Sci. Technol. 47, 6646-6655.

Collard, F., Gilbert, B., Eppe, G., Parmentier, E., Das, K., 2015. Detection of anthropogenic particles in fish stomachs: An isolation method adapted to identification by raman spectroscopy. Arch. Environ. Contam. Toxicol. 69, 331-339.

Derraik, J.G., 2002. The pollution of the marine environment by plastic debris: a review. Mar. Pollut. Bull. 44, 842-852.

Dris, R., Gasperi, J., Saad, M., Mirande, C., Tassin, B., 2016. Synthetic fibers in atmospheric fallout: a source of microplastics in the environment? Mar. Pollut. Bull. 104, 290-293.

Dris, R., et al., 2017. A first overview of textile fibers, including microplastics, in indoor and outdoor environments. Environ. Pollut. 221, 453- 458.

Eriksen, M., et al., 2013. Microplastic pollution in the surface waters of the Laurentian Great Lakes. Mar. Pollut. Bull. 77, 177-182.

Farrell, P., Nelson, K., 2013. Trophic level transfer of microplastic: Mytilus edulis (L.) to Carcinus maenas (L.). Environ. Pollut. 177, 1-3.

Hidalgo-Ruz, V., Gutow, L., Thompson, R.C., Thiel, M., 2012. Microplastics in the marine environment: a review of the methods used for identification and quantification. En- viron. Sci. Technol. 46, 3060-3075.

Imhof, H.K., Schmid, J., Niessner, R., Ivleva, N.P., Laforsch, C., 2012. A novel, highly efficient method for the separation and quantification of plastic particles in sediments of aquatic environments. Limnol. Oceanogr. Methods 10, 524-537.

INSEE, National Institute of Statistics and Economic Studies, 2013. https://www.insee.fr/ fr/statistiques/2387611? sommaire $=2119504$.

International Cotton Advisory Committee, 2017. World Textile Demand Report: World Consumption of Major Textile Fibers.

Ladewig, S.M., Bao, S., Chow, A.T., 2015. Natural fibers: a missing link to chemical pollution dispersion in aquatic environments. Environ. Sci. Technol. 49, 12609-12610. 
Lechner, A., et al., 2014. The Danube so colourful: a potpourri of plastic litter outnumbers fish larvae in Europe's second largest river. Environ. Pollut. 188, 177-181.

Lusher, A.L., McHugh, M., Thompson, R.C., 2013. Occurrence of microplastics in the gastro- intestinal tract of pelagic and demersal fish from the English Channel. Mar. Pollut. Bull. 67, 94-99.

Lusher, A.L., Burke, A., O'Connor, I., Officer, R., 2014. Microplastic pollution in the Northeast Atlantic Ocean: validated and opportunistic sampling. Mar. Pollut. Bull. 88, $325-333$.

Lusher, A.L., Tirelli, V., O'Connor, I., Officer, R., 2015. Microplastics in Arctic polar wa- ters: the first reported values of particles in surface and sub-surface samples. Sci Rep 5, 14947.

Mani, T., Hauk, A., Walter, U., Burkhardt-Holm, P., 2015. Microplastics profile along the Rhine River. Sci. Rep. 5, 17988.

McCormick, A., Hoellein, T.J., Mason, S.A., Schluep, J., Kelly, J.J., 2014. Microplastic is an abundant and distinct microbial habitat in an Urban River. Environ. Sci. Technol. $48,11863-11871$.

Mintenig, S., Int-Veen, I., Löder, M., Gerdts, G., 2014. Mikroplastik in ausgewählten Kläranlagen des Oldenburgisch Ostfriesischen Wasserverbandes (OOWV) in Niedersachsen. Alfred-Wegener-Institut, Helmholtz-Zentrum für Polar-und Meeresforschung.

Moore, C.J., Lattin, G.L., Zellers, A.F., 2011. Quantity and type of plastic debris flowing from two urban rivers to coastal waters and beaches of southern. J. Integr. Coast. Zone Manag. 11, 65-73.

Murphy, F., Ewins, C., Carbonnier, F., Quinn, B., 2016. Wastewater treatment works (WwTW) as a source of microplastics in the aquatic environment. Environ. Sci. Technol. 50, 5800-5808.

Norén, F., 2007. Small Plastic Particles in Coastal Swedish Waters-Kimo Reports.

Remy, F., et al., 2015. When microplastic is not plastic: the ingestion of artificial cellulose fibers by macrofauna living in seagrass macrophytodetritus. Environ. Sci. Technol. 49, $11158-11166$.

Rochman, C.M., Browne, M.A., 2013. Classify plastic waste as hazardous. Nature 494, 169-171.

Sanchez, W., Bender, C., Porcher, J.-M., 2014. Wild gudgeons (Gobio gobio) from French rivers are contaminated by microplastics: preliminary study and first evidence. Environ. Res. 128, 98-100. 
Talvitie, J., et al., 2015. Do wastewater treatment plants act as a potential point source of microplastics? Preliminary study in the coastal Gulf of Finland, Baltic Sea. Water Sci. Technol. 72, 1495-1504.

Tourinho, P.S., Ivar do Sul, J.A., Fillmann, G., 2010. Is marine debris ingestion still a prob- lem for the coastal marine biota of southern Brazil? Mar. Pollut. Bull. 60, 396401.

Vilmin, L., Flipo, N., de Fouquet, C., Poulin, M., 2015. Pluri-annual sediment budget in a navigated river system: the Seine River (France). Sci. Total Environ. 502, 48-59.

Yonkos, L.T., Friedel, E.A., Perez-Reyes, A.C., Ghosal, S., Arthur, C.D., 2014. Microplastics in four estuarine rivers in the Chesapeake Bay, U.S.A. Environ. Sci. Technol. 48, 14195-14202.

Zhang, K., Gong, W., Lv, J., Xiong, X., Wu, C., 2015. Accumulation of floating microplastics behind the Three Gorges Dam. Environ. Pollut. 204, 117-123. 